Article

\title{
Religious Freedom and the Limits of Propagation: Conversion in the Constituent Assembly of India
}

\author{
Sarah Claerhout and Jakob De Roover* \\ Department of Comparative Science of Cultures, Ghent University, 9000 Ghent, Belgium; \\ sarah.claerhout@ugent.be \\ * Correspondence: jakob.deroover@ugent.be
}

Received: 12 December 2018; Accepted: 26 February 2019; Published: 5 March 2019

\begin{abstract}
In discussions about religious freedom in India, the country's conflict regarding conversion plays a central role. The Constitution's freedom of religion clause, Article 25, grants the right "freely to profess, practise and propagate religion," but this has generated a dispute about the meaning of the right 'to propagate' and its relation to the freedom to convert. The recognition of this right is said to be the result of a key debate in the Constituent Assembly of India. To find out which ideas and arguments gave shape to this debate and the resulting religious freedom clause, we turn to the Assembly's deliberations and come to a surprising conclusion: indeed, there was disagreement about conversion among the Assembly members, but this never took the form of a debate. Instead, there was a disconnect between the member's concerns, objections, and comments concerning the draft article on the one hand, and the Assembly's decision about the religious freedom clause on the other. If a key 'debate' took this form, what then could the ongoing dispute concerning conversion in India be about? We first examine some recent historiographical accounts of the Indian conflicts about conversion and proselytization. Then we develop a hypothesis that aims to make sense of this enduring conflict by identifying a blindness at its core: people reasoning against the background of Indian traditions see 'propagation of religion' as the human dissemination of tradition; this is incompatible with a religious conception where conversion and propagation of faith are seen in terms of God's intervention. These two ways of seeing 'propagation' generate two conflicting experiences of the Indian dispute about religious freedom and conversion.
\end{abstract}

Keywords: freedom of religion; conversion; the right to propagate religion; India; Constitution of India; Indian traditions; Christianity

\section{Introduction}

The issue of religious conversion complicates any discussion about the right to freedom of religion in post-Independence India. Disputes about conversion and religious truth have led to mutual incomprehension between different groups in Indian society for at least two centuries. Over the past decades, calls for restrictions on certain types of conversion have frequently been made in political and legal debate. Several Indian states passed bills banning the use of force, fraud, and allurement in conversion, called 'Freedom of Religion Acts'. This type of legislation has led to concerns about religious intolerance and discrimination against Christian and Muslim minorities: the legal restrictions on conversion are said to threaten the right to freedom of conscience and religion (Ahmad 2018; Coleman 2008; Huff 2009; Jenkins 2008). Others, however, argue that the practice of conversion itself constitutes a violation of the freedom of religion; in their eyes, the attempt to try and convert others to one's own religion involves a violent intrusion into a person's religious life (Dayananda 1999).

Article 25(1) of the Constitution of India of 1950 often makes its appearance in these disputes: "Subject to public order, morality and health and to the other provisions of this Part, all persons 
are equally entitled to freedom of conscience and the right freely to profess, practise and propagate religion." Scholars suggest that the Constituent Assembly, the body that drafted the Indian Constitution between 1946 and 1949, decided to include the right to propagate religion among the fundamental rights of India's citizens after a key debate, which ended in a victory for the more liberal-minded Assembly members over Hindu traditionalists who had opposed conversion and the right to propagation of religion (e.g., Josh 2009, p. 101; Jaffrelot 2010, pp. 155-56). According to this account, the Assembly's deliberations led to the recognition of a constitutional right which grants the freedom to propagate and convert.

Given the importance attributed to this debate, we will start by raising some questions: What was the nature of the Assembly's deliberations about the right to propagate religion? Why did this constitution-making body decide to add the term 'propagate' to the more common 'profess' and 'practise' in this clause? What were the different standpoints and arguments that gave shape to the debate and how did these lead to the approval of Article 25 and the right to freely propagate religion? The Constituent Assembly took years to draft the Constitution. It is reasonable to expect that this body would formulate and discuss the problems related to religious freedom in India with some care, since its aim was to provide the fundamental principles according to which the Indian nation should be governed. Hence, we turn to the Assembly's records to discover what its members had to say about religious freedom, conversion, and the propagation of religion.

\section{Propagation and Conversion in the Constituent Assembly}

How was the right to propagate religion introduced into the text of the Indian Constitution? Several earlier documents-such as the Constitution of India Bill (1895), The Commonwealth of India Bill (1925), The Nehru Report (1928), and Karachi Resolution (1931)—had recognized religious freedom as a fundamental right that should be part of a new constitution; some mentioned the freedom 'to profess and practise' but none included a right 'to propagate religion'. ${ }^{1}$ The only text with a similar formula was a note titled States and Minorities, composed by B. R. Ambedkar, the later chairman of the Drafting Committee. It said: “The State shall guarantee to every Indian citizen liberty of conscience and the free exercise of his religion including the right to profess, to preach and to convert within limits compatible with public order and morality" (Ambedkar 1947). Ambedkar submitted this note to the Assembly's Sub-committee on Fundamental Rights in 1947, but it did not play any central role in the drafting of the new Constitution.

Two other preparatory notes served as the starting point for the discussions of the Advisory Committee on Fundamental Rights, Minorities and Tribal and Excluded Areas and its Sub-committee on Fundamental Rights ${ }^{2}$ : one by K. M. Munshi, a member of the Indian National Congress and lawyer, and the other by B. N. Rau, a colonial civil servant and former judge who had been appointed as the Constitutional Advisor. Neither of these mentioned the freedom to propagate religion. In fact, Munshi's initial draft articles concerning the right to religious freedom had sub-clauses that put restrictions on conversion:

(6) No person under the age of eighteen shall be free to change his religious persuasion without the permission of his parent or guardian. (7) Conversion from one religion to another brought about by coercion, undue influence or the offering of material inducement is prohibited and is punishable by the law of the Union. (Rao 2015, p. 76)

1 These were significant documents, since the members of the Constituent Assembly made use of them for their preparations. For instance, K. M. Munshi in his preparatory note on fundamental rights, referred to The Nehru Report, the Karachi Resolution and the Sapru Report to advocate the inclusion of fundamental rights in the new Constitution (Rao 2015, p. 71)).

2 On 27 February 1947 this Advisory Committee created five Sub-committees, including one that would deal with Fundamental Rights and another that focused on Minorities. 
At the first meeting, the Sub-committee on Fundamental Rights decided to examine Munshi's draft in conjunction with other drafts. His draft clause was adopted with minimal revisions, without any discussion about the phrase "freely to profess and practise religion" (Rao 2015, pp. 116-24). The clause that prevented minors from changing religious persuasion without the permission of the parents or guardian was accepted in a revised form, which now just banned conversion of any person under the age of 18 (Rao 2015, pp. 124-25). All these clauses were included in the draft report of the Sub-committee on Fundamental Rights with minor changes (Rao 2015, p. 140).

Next, the question of fundamental rights was examined by the Sub-committee on Minorities and it is here that the term 'propagate' suddenly made its appearance (Rao 2015, pp. 208-9). From the minutes, it may be noted that a Tamil member educated at the Universities of Oxford and Cambridge, Mariadas Ruthnaswamy, argued "that certain religions, such as Christianity and Islam, were essentially proselytizing religions, and provision should be made to permit them to propagate their faith in accordance with their tenets ... " (Rao 2015, p. 201). No further reasons were offered as to the necessity of such a provision or why it should take the form of a fundamental right to propagate religion.

From the discussion in the Advisory Committee, we know that it was a priority to reach decisions that would fully satisfy the minorities. Its chairman, Vallabhbhai Patel, reminded the Committee members of their task to protect minorities and referred to a discussion in the British Parliament where it had been claimed "on behalf of the British Government that they have a special responsibility-a special obligation - for the protection of the interests of the minorities." "They claim," so the chairman continued, "to have a more special interest than we have." He objected: "It is for us to prove that this is a bogus claim, a false claim, and that nobody can be more interested than us in India in the protection of our minorities." "Our mission," Patel concluded, "is to satisfy every one of them and we hope we shall be able to satisfy every interest and safeguard the interests of all the minorities to their satisfaction" (Rao 2015, pp. 61-66). One could infer from this that the right to propagate religion was introduced to 'fully satisfy' the Christian minority and safeguard its interests, but this is not stated anywhere in the Committee proceedings.

In fact, when the Advisory Committee turned to the religious freedom clause, several members argued that the freedom to 'propagate' was superfluous, since it fell under the freedom of speech and expression. As one member put it: "The propagation of religion is amply assured in clause 10 dealing with freedom of speech and expressions." Moreover, she argued: "Since conversion by force or undue influence only is to be banned, it follows that conversion of an adult to any religion by reason of conviction will be permissible" (Rao 2015, pp. 211-13). Several others agreed that granting the freedom of speech and expression should be sufficient, since 'propagation of religion' was but a specific instance of speech. In response, Ruthnaswamy defended the inclusion of the phrase 'to propagate'-a well-known word, according to him, including "not only preaching but other forms of propaganda made known by modern developments like the use of films, radio, cinemas and other things." Munshi then argued that it was precisely because of this wide-ranging meaning of 'propagation' that he opposed including it in the Constitution: "The word might be brought, I think, to cover even forced conversion." "So far as the 'freedom of speech' is concerned," he suggested, "it carries sufficient authority to cover any kind of preaching." He again stressed the lack of clarity as to the meaning of the term: "If the word 'propaganda' means something more than preaching, you must know what it is and therefore I was opposed to this introduction of the word 'propaganda'" (Rao 2015, pp. 267-68).

The Committee members were unclear as to what 'propagating religion' meant. Several members appeared to equate it to 'doing propaganda' and used the terms as though they were synonyms. The 'propagation of religion' would then become a form of propaganda, like propaganda for any set of ideas or ideologies or social and political movements. In that case, it is but a specific instance of speech already protected by the right to freedom of speech and expression. Ruthnaswamy and Munshi exchanged a few sentences about the meaning of 'propagate' but this did not clarify the meaning of the word in the constitutional clause. Instead of figuring out the nature of the disagreement, the exchange ended as follows: 
Govind Ballabh Pant: At worst it is redundant and as so many members want it we had better introduce it.

\section{K. M. Munshi: It is not a redundant word.}

Chairman: Let us takes votes on it. Those who are in favour of retaining the word "propagate" may raise their hands. (The amendment was accepted). (Rao 2015, p. 268)

This does not tell us much: the 'arguments' for and against introducing the right to propagate religion were limited to a handful of rudimentary claims that mentioned 'proselytizing religions' and 'propaganda'; the disagreement about the clause was not explored further; consequently, no clarity was created about the points of disagreement to be discussed in the plenary Assembly. It was simply set aside by reducing the question to one of voting for or against retaining a specific word in the Constitution, without knowing what this word 'propagate' meant and what the right would imply.

\subsection{Conversion as a Fundamental Right?}

The next relevant exchange took place in a plenary meeting of the Constituent Assembly on 1 May 1947, where the Interim Report on Fundamental Rights was to be discussed. Initially, the proposed clause 13, which included the right "freely to profess, practise and propagate religion", was accepted and nothing noteworthy happened during the meeting. ${ }^{3}$ However, when Munshi moved an amendment about the conversion of minors, this caused upheaval: "Any conversion from one religion to another of any person brought about by fraud, coercion or undue influence or of a minor under the age of 18 shall not be recognized by law" (CAD, 1 May 1947; italics ours). ${ }^{4}$ At stake was the second part of this amendment, which would in effect prohibit conversion under the age of 18. Immediately, several members interfered by pointing out that Munshi's amendment implied a negation of the previously endorsed clause on the freedom to propagate.

From the proceedings, however, we cannot get clarity as to what the disagreement was about. Two Christian Assembly members stated that the right to propagate religion had been recognized but would now be taken away by the proviso 'of a minor under the age of 18'. The Anglo-Indian representative Frank Anthony emphasized that "conversion under undue influence, conversion by coercion or conversion by fraud should not be recognized by law." He added: "My community does not propagate. We do not convert, nor are we converted. But I do appreciate how deeply, how passionately millions of Christians feel on this right to propagate their religion." Therefore, Anthony objected to the attempt to restrict this right:

I want to congratulate the major party for having, in spite of its contentious character, retained the words 'right to practise and propagate their religion'. Having done that, I say that after giving with one hand this principal fundamental right a right [sic] which is regarded as perhaps the most fundamental of Christian rights, do not take it away by this proviso, 'or of a minor under the age of $18^{\prime}$. (CAD, 1 May 1947)

To Anthony, the right to propagate was a "principal fundamental right," which would be undermined by adding the amendment about minors: "I say that if you have this particular provision, or if you place an absolute embargo on the conversion of a minor, you will place an embargo absolutely on the right of conversion." He concluded: "You will virtually take away the right to convert." This

3 Clause 13 read: "All persons are equally entitled to freedom of conscience, and the right freely to profess, practise and propagate religion, subject to public order, morality or health, and to the other provisions of this Part" (CAD, 1 May 1947, Vallabhbhai Patel).

4 Our references to the Constituent Assembly Debates (CAD) give the date of the discussion and the name of the Assembly member making the intervention. This information allows the reader to consult the relevant records which are available online. We made use of the version on the website of the Lok Sabha, the lower house of the Indian Parliament, via the following direct link: http:/ /164.100.47.194/Loksabha/Debates/cadebadvsearch.aspx. We also consulted the version on a website developed by the Constitutional and Civic Citizenship Project (http:/ / cadindia.clpr.org.in/). 
will be the result, because no parent will adopt Christianity when the effect is that of creating a divide between children and parents. Anthony reiterated: "You may have your prejudices against conversion; you may have your prejudices against propagation. But once having allowed it, I plead with you not to cut at the root of family life." He also appreciated the safeguards about undue influence, fraud and coercion and realized "how deeply certain sections of this House feel on this question of conversion." "But," he asked, "having once conceded the right to propagate, to concede this in consonance with the principles of family law and in consonance with the principles of natural law and justice" (CAD, 1 May 1947, Frank R. Anthony).

Another member, the Reverend J. J. M. Nichols-Roy stressed that the amendment would prevent minors from exercising their own consciences. Drawing on his own conversion experience at age fifteen, Nichols-Roy argued as follows:

... [T] think that a youth under the age of eighteen does not have a conscience before God and, therefore, he cannot express his belief is wrong. ... There is a spiritual side in conversion which ought to be taken notice of by this House. Conversion does not mean only that a man changes his form of religion from one religion to another or adopts a different name of religion, such as, a Hindu becomes a Christian. But there is the spiritual aspect of conversion, that is, the connection of the soul of man with God, which must not be overlooked by this House. I know there are those who change their religion being influenced by material considerations, but there are others who are converted being under the influence of spiritual power. When a boy feels that he is called by God to adopt a different faith, no law should prevent him from doing that. (CAD, 1 May 1947)

Emphasizing the spiritual dimension, Nichols-Roy insisted that the amendment about minors was "absolutely wrong," for it "will oppress the consciences of the youths who want to exercise their religious faiths before God." Since the freedom to convert is inherently connected to the relation between the conscience and the spiritual forces of God, Nichols-Roy argued, a law that puts an age limit would be oppressive to the conscience. This implies not only that the freedom to convert should be guaranteed by law, but also that other laws must be subordinated to it: "This freedom I consider to be a Fundamental Right of the youths. No law should be made which will work against good spiritual forces." Nevertheless, Nichols-Roy clearly expressed his objections "against any conversion by undue influence or by fraud or coercion" (CAD, 1 May 1947).

Several elements are significant in these two interventions. Firstly, it is crucial for these members that the fundamental right to propagate religion implies a recognition of the freedom to convert for all persons, including minors. This "is regarded as perhaps the most fundamental of Christian rights." Any attempt to curb the right to propagate religion, by introducing an age limit or similar constraints, amounts to placing an "embargo absolutely on the right of conversion." Secondly, this is clarified by introducing the idea that each human being has a conscience connected to God and each individual can feel that he or she is being called by Him. One should always be free to convert from one religion to the other, if this happens under the influence of spiritual forces. Thirdly, the use of force, fraud and allurement in attempts to convert people is unacceptable and falls outside the boundaries of genuine conversion. But if conversion is a free act of the conscience, then it should not be restricted in any way, for the conscience cannot be oppressed by any law. In this sense, the freedom to propagate and convert is a fundamental and inalienable human right. Finally, Anthony suggests that other Assembly members are inspired by prejudices against conversion and propagation. He understands the objections raised against the conversion of minors as a result of preconceived opinion, ignorance or bias about the subject.

These interventions were followed by a long statement by Purushottamdas Tandon, a famous Congress leader and freedom fighter, who claimed to speak on behalf of other Congress members. Tandon voiced his surprise: "Mr. President, I am greatly surprised at the speeches delivered here by our Christian brethren." "Some of them have said that in this Assembly we have admitted the right 
of every one to propagate his religion and to convert from one religion to another." This is wrong, he argued:

We Congressmen deem it very improper to convert from one to another religion or to take part in such activities and we are not in favour of this. In our opinion it is absolutely futile to be keen on converting others to one's faith. But it is only at the request of some persons, whom we want to keep with us in our national endeavour that we accept this. Now it is said that they have a right to convert young children to their faith. What is this? Really this surprises me very much. (CAD, 1 May 1947)

For Tandon, the right to propagation of religion did not entail a general freedom to try to convert others to one's religion. He considered converting others to one's faith as a futile endeavour, which becomes improper when it involves children. Tandon also said that the right to propagate was kept "out of regard for our Christian friends," as a pragmatic step to include the Christians in "the national endeavour'. He suggested that the Congressmen wanted to carry the Christians along, by accommodating their insistence on the right to propagate (CAD, 1 May 1947). In spite of his surprise, Tandon makes no effort to make sense of what the Christian representatives had said about the right to propagate and convert. In fact, when he and other Congress members intervene, they largely ignore the statements and concerns voiced by Anthony and Nichols-Roy. There is no attempt to find out why these two find the freedom to convert so important and what their claims about the conscience and God mean. Instead, these other members expressed utter astonishment at the claim that the Assembly had recognized a right to convert young children to Christianity.

Tandon used an analogy to clarify the difficulty: "If a boy of eighteen executes a transfer deed in favour of a man for his hut worth only Rs. 100, the transaction is considered unlawful," but "our brethren come forward and say that the boy has enough sense to change his religion." This is both improper and unreasonable, in Tandon's eyes: "You can convert a child below eighteen by convincing and persuading him but he is a child of immature sense and legally and morally speaking this conversion can never be considered valid" (CAD, 1 May 1947; italics ours). From this perspective, conversion of a child can only take place through force, fraud or allurement. Therefore, Tandon could also suggest the following: "It is proper that a boy should be allowed to formally change his religion only when he attains maturity." He did not advocate a general rejection of 'conversion' as the changing of one's religion, since this act is unproblematic once one attains 'maturity'. Countering Anthony's remark that what had been given with the right hand (clause 13) was taken away with the left hand (clause 17), Tandon stressed: "What we gave them with our right hand is that they have a right to convert others by an appeal to reason and after honestly changing their views and outlook. The three words, 'coercion', 'fraud' and 'undue influence' are included as provisos and are meant to cover the cases of adult converts" (CAD, 1 May 1947; italics ours). The gap between Nichols-Roy and Tandon is striking: the first assumed that minors, like adults, have an innate conscience that should always be free to respond to God's call; the second emphasized reason or intellect, which needs to be cultivated and formed before individuals can make appropriate decisions about changing religion. But this gap between their respective understanding of 'conversion' is not even noted, let alone debated.

More generally, the participants in this discussion made no attempt to understand or address each other's concerns and arguments. Algu Rai Shastri explained why the conversion of minors was deplorable: "We want such an amendment in this clause of Fundamental Rights that a person who wants to change his religion should be able to do so only after he is convinced through cool deliberation that the new religion is more satisfactory to him than the old one" (CAD, 1 May 1947). Shastri too emphasized that the problem is not the change of religion per se. If a mature person comes to the realization that he wants to change his religion, this is perfectly acceptable, but not for children:

If we permit minors to be transferred like trees on land with the newly embraced religion of their parents, we would be doing an injustice. Many fallacious arguments are offered to permit this. We must not be misled by these. We know that our failure to stop conversion 
under coercion would result in grave injustice. I have a right to change my religion. I believe in God. If I realize tomorrow that God is a farce and an aberration of human mind then I can become an atheist. If I think that the Hindu faith is false, I, with my grey hair, my fallen teeth and ripe age, and my mature discretion can change my religion. But if my minor child repeats what I say, are you going to allow him also a right to change his religion (at that age)? (CAD, 1 May 1947, Algu Rai Shastri; italics ours)

Again, the suggestion is that citizens should be allowed to convert, only if this happens after 'cool' deliberation and reasoning. The idea that conversion is a question of 'cool deliberation' and 'mature discretion' is far away from the Christian conception of this process as a response of the conscience to God's spiritual forces, which had come to the surface in Nichols-Roy's intervention. Even though Shastri stressed how absurd it would be for him to give a minor a right to change religions, he did not pause to think about why this was not absurd at all to his Christian colleagues.

Yet another Assembly member, Jagat Narain Lal, pointed out that the right to propagate had not been included to such an extent in the Constitution of any other country: "My submission is that this House has gone to the farthest limit possible with regard to minorities, knowing well the fact that there are a few minorities in this country whose right to carry on propaganda extends to the point of creating various difficulties." Lal supported Tandon's standpoint that the inclusion of this "right to do propaganda" is a concession towards the Christians, granted in spite of the fact that "most of the Congress members of this House" did not want to keep this right. "The fact is that we desire to make the minorities feel that the rights which they had been enjoying till now shall be allowed to continue within reasonable limits by the majority. We have no desire to curtail them in any way. But we do not concede the right to do propaganda" (CAD, 1 May 1947). The recognition of this fundamental right is about having the minorities feel that they will continue to enjoy the same rights but within reasonable limits. The language use again suggests that the right to propagate religion is equivalent to the right to 'do propaganda'. For the Christian members, however, the right to propagate religion clearly meant something very different, since it is rooted in the relationship between the conscience and God.

The different participants in this exchange agreed about banning the use of fraud, coercion or undue influence in conversion; they also admitted that changing between religions should be possible. What was the problem then? Some interventions emphasized the freedom of conscience of minors. Others reflected concerns about mass conversions or about the status of children whose parents have converted. Yet others stressed that children are too immature to make decisions about changing from one religion to another. We also know that there were worries about the impact of Christian schools and their attempts to convert Hindu children, or about the minorities and their position in post-Independence India. Judging from the reports, however, it is unclear what exactly was at stake, beyond the fact that the Assembly members disagreed about the conversion of minors.

This intense disagreement stands in contrast to the way in which the exchange about Munshi's amendment was brought to an end. Ignoring the above interventions, the discussion was ended by Ambedkar, who intervened and asked Munshi to drop the amendment. The gist of Ambedkar's argument was that this clause would end up forcing parents to be separated from their children merely because they adopted another religion. He did not clarify how the amendment could be modified to avoid this, but only made a mysterious reference to the 'several Assembly committees' that had already dealt with this issue. He then rejected the proposition, because it "would lead to many disruptions, to so many evil consequences" (CAD, 1 May 1947). In other words, Ambedkar announced that the amendment should be rejected without addressing any of the objections. Consequently, it was decided to refer clause 17 back to the Advisory Committee on Fundamental Rights and Minorities, which eventually rejected it.

\subsection{What Is Propagation?}

When the Assembly discussed the religious freedom clause once more in December 1948, the use of the word 'propagate' generated more discontent and confusion; hence, several members moved 
amendments to remove the term or revise the clause. However, rather than being a debate about the disagreements and the proposed amendments, the meeting took the form of a seemingly random sequence of statements of opinion by Assembly members, who neglected to respond to each other and eventually did not even defend their own objections to the clause.

Tajamul Hussain, a Muslim representative, suggested replacing the words "practise and propagate religion" by "practise religion privately." "Why should you interfere with my religion," he asked, "and why should I interfere with your religion?"

Supposing I honestly believe that I will attain salvation according to my way of thinking, and according to my religion, and you Sir, honestly believe that you will attain salvation according to your way, then why should I ask you to attain salvation according to my way, or why should you ask me to attain salvation according to your way? (CAD, 3 December 1948)

If we accept this proposition, he asked, then "why propagate religion?" "Do not demonstrate it for the sake of propagating," he continued: "Do not show to the people that this is your religion for the sake of showing." Hussain's conclusion was clear: "If you start propagating religion in this country, you will become a nuisance to others. So far it has become a nuisance" (CAD, 3 December 1948). Clearly, this Indian Muslim shared the objections against granting a constitutional right to propagate religion and found interfering with the religions of others objectionable.

Several Assembly members moved other amendments to curb the right to propagate. The socialist K.T. Shah argued for a prohibition against propagation of religion in educational institutions, asylums and hospitals, institutions for the elderly, etc. What one should recognize is "the right that anybody professing any particular form of belief should be at liberty, in this Liberal State, to place the benefits or beauties of his particular form of worship before others." But conversion can only happen after mature consideration, which is impossible for children, people of unsound mind, etc. Shah wanted to make sure that "minds not quite free from other influences, minds suffering from some kind of handicap, shall not be unduly influenced." This provision was necessary, according to him, to prevent abuse of the freedom to propagate. As he put it, this was a question of decency: "When you meet at a social gathering or congregational union this much decency should be observed that you shall not carry on your influence in an undue manner, but only rely upon the convincing character of your arguments" (CAD, 3 December 1948). Again, we note the emphasis put on the role of the intellect and reason in deciding about religion and conversion.

The Assam delegate Rohini Kumar Chaudhari contributed by stating that he had no objection to the propagation of any religion: "If anyone thinks that his religion is something ennobling and that it is his duty to ask others to follow that religion, he is welcome to do so." But, he continued, "what I would object to is that there is no provision in this Constitution to prevent the so-called propagandist of his religion from throwing mud at some other religion." 'Throwing mud' referred to the fact that missionaries had gone around the country and "described Sri Krishna in the most abominable terms" and decried the worship of idols and called them names. According to Chaudhari, it made no sense for followers of one specific religion to denigrate another simply because it had unsatisfactory features. More objections to the right to propagate religion were voiced by Lokanath Misra, who called the religious freedom clause, then Article 19, "a Charter for Hindu enslavement" (CAD, 3 December 1948). In his eyes, the introduction of this right created a great danger: on the one hand, the Constitution was "tabooing religion" in the sense that the secular state would by-pass the ancient culture of the land; on the other hand, it showed the "unjust generosity" of making propagation of religion a fundamental right. Together, this could only "mean paving the way for the complete annihilation of Hindu culture, the Hindu way of life and manners." Like others before him, Misra concluded with a plea to drop the word 'propagate' (CAD, 6 December 1948).

Each of these interventions was largely disconnected from the others; only very rarely did members address the statements made by their fellow members. The meeting meanders between speeches about the survival of the Hindu religion, the place of religion in educational institutes and 
hospitals, the meaning of 'secularism', 'religion' and 'dharma', etc. In other words, the Constituent Assembly 'debates' about the fundamental right to religious freedom show an absence of debate. Again, all the interventions and amendments concerning the clause were ignored in the drafting of the Constitution. In fact, when the Vice-President concluded the debate, he called upon Ambedkar to reply to the amendments in his role as the chair of the Drafting Committee. Ambedkar said he had nothing to add to the speakers who spoke in support of this article and that he was prepared to accept only one amendment (CAD, 6 December 1948). A member was dissatisfied: "May I ask whether it will be enough if Dr. Ambedkar says: 'I oppose: I have nothing to say'. I should think that in fairness to the House, he should reply to the points raised in the amendments and during the debate" (CAD, 6 December 1948, H. V. Kamath). The Vice-President replied: "I am afraid we cannot compel Dr. Ambedkar to give reasons for rejecting the various amendments." With this, the debate came to an end, all amendments excepting one were rejected, and the right to propagate religion was incorporated into Article 25 of the Constitution.

Ambedkar's role epitomizes the nature of these exchanges in the Constituent Assembly. As the chair of the Drafting Committee, he had no special power to decide about the fate of amendments in the plenary Assembly. Still, his choosing to accept or reject amendments to the religious freedom clause ended up playing a decisive role. He refused to give reasons for rejecting the proposed amendments and ignored whatever had been said by his fellow Assembly members in favor of the amendments. Yet, these members did not attempt to intervene or defend their objections to this clause on the freedom of religion. Once they had to vote about the constitutional clause and the amendments, they appeared to become indifferent to their own objections and concerns. As a result, the Assembly's vote simply followed Ambedkar's dictate.

Moreover, even though many of the interventions revealed ignorance about the right to religious freedom, conversion, and the meaning of 'propagation of religion', the Assembly never called upon any experts, available scholarship, or background information to clarify the issues at hand. Consequently, at the end of the discussion, it remained equally unclear as before as to what the relation was between the right to propagate religion and the freedom to convert, what 'propagating' religion meant, and how the dispute about religious conversion should be made sense of. To conclude, the Assembly's sessions did not consist of a reasonable debate which could lead to justified decisions about the content of the constitutional religious freedom clause. Instead, in a matter as significant as the right to freedom of religion, there was a major disconnect between the utterances and concerns of the Assembly members on the one hand, and the eventual decisions about the clause that would become Article 25 of the Constitution on the other.

\section{Historiographical Accounts}

How can we make sense of the Constituent Assembly's debates about the right to profess, practice, and propagate religion? We could turn to the wide range of scholarship on religious conversion and proselytization in India. Most of this scholarship consists of historical, descriptive, and anthropological works (e.g., Harding 2008; Heredia 2007; Roberts 2016; Robinson and Clarke 2003). Some authors address the conflicts related to conversion, proselytism, and religious freedom in India (Adcock 2014; Bauman 2015; Osuri 2013; Sarkar 2007; Viswanathan 1998); a few works also examine the relevant debates in the Constituent Assembly (Josh 2009; Kim 2003). What the historiographical accounts have in common is that they focus on the decades preceding the Indian Independence of 1947 to explain the disputes that occurred in the Constituent Assembly and afterwards, that is, they connect the controversies about conversion and propagation of religion in post-Independence India to a set of historically specific concerns and discourses which emerged from the events and developments of the late colonial period.

Consider one such historiographical account. In her Limits of Tolerance (Adcock 2014), C. S. Adcock explains the distrust towards conversion and proselytization in contemporary India in terms of a distinctive Indian ideal of "Tolerance," which was central to the Gandhian tradition and became 
a commonplace of Indian secularism. This ideal rests on a distinction between "proselytizing" and "non-proselytizing" religions and is critical of "proselytizing religion" because of its alleged intolerance stemming from dogmatic and exclusive truth claims. Adcock claims that the "Tolerance" discourse builds on this distinction to develop a specific critique of religious freedom; it suggests that recognizing the freedom to convert and proselytize as a part of the right to religious freedom privileges "proselytizing religions" and is unsuited to the Indian cultural context. This ideal of "Tolerance" should not be viewed as a timeless Hindu attitude, she argues, since it emerged from specific historical and political conditions, such as the disputes about the shuddhi movement of the Arya Samaj (a Hindu reform movement which sought to convert Muslims and others to 'the pure and eternal religion of the Vedas') and its Islamic counterpart of tabligh during the 1920s and 1930s. Moreover, this discourse drew upon the conceptual vocabulary developed by the comparative study of religion in Britain and Europe (Adcock 2014). Continuing along the lines of Adcock's argument, one could suggest that the participants in the Constituent Assembly debates were the heirs to this historically specific set of discourses about conversion, which had emerged from the interreligious polemics in British India (involving organizations such as the Arya Samaj, Tablighi Jamat, the Society for the Propagation of Christian Knowledge, etc.) and borrowed from British colonial law and politics and the language of European comparative religion. In brief, the disputes about conversion and proselytization in the Assembly were shaped by historically specific ideas and events that unfolded during the first half of the 20th century.

This type of account is home to basic problems. For one, the specific vocabulary used by some members of the Constituent Assembly undoubtedly borrowed from the discourse of the Gandhian political tradition and from verbiage popular in the 'interreligious' polemics of earlier decades; some of these terms and phrases also originated in the comparative study of religion in Europe. However, the relevant Assembly members used this English-language vocabulary to try and articulate particular concerns and stances which were already visible from the early $18^{\text {th }}$ century. Moreover, several members also used a different conceptual vocabulary that cannot be attributed to late colonial interreligious polemics or the discourse about "Tolerance." In fact, as we have shown elsewhere, the conflicts about conversion in India show recurring concerns, patterns, and clusters of ideas that have surfaced again and again from the early modern period to contemporary disputes (Claerhout and De Roover 2005, 2008).

On the one hand, Christian Assembly members drew upon centuries of conceptual developments within Christian theology when they invoked the oppression of the conscience, the connection between the soul and God, and spiritual forces working upon the individual as factors central to the process of conversion. Naturally, Christian thinking concerning conversion has shown discontinuities, shifts, and distinct conceptual elaborations from the early middle ages until today. Nevertheless, it does reveal a central set of concerns and concepts that recur over and over again. For instance, the question of whether the conscience should always be free and forced conversion ought to be off limits; the nature and steps of the process whereby the individual believer can turn towards Christ, submit to God, and find spiritual freedom; the way in which conversion depends on the workings of the Holy Spirit rather than on human effort; etc. For more than fifteen centuries, the process of conversion and its relation to the spreading of Christian religion has been one of the major concerns of Christians from different denominations, eras, and regions. ${ }^{5}$ That terms such as 'proselytization' and 'religious freedom' were introduced only at a particular point in time to conceptualize dimensions of this process cannot deny the recurrent patterns in Christian reasoning and practices related to conversion.

On the other hand, the interventions of the Assembly members with a background in the Hindu traditions reflected stances and concerns that had been expressed regularly in the period from the late

5 From the vast literature on the process of conversion, see: (Armstrong and Wood 2000; Citron 1951; Harran 1983; Morrison 1992; Muldoon 1997; Tellenbach 1991; Wicks 1992). 
17th century to the mid 19th century: the incomprehension towards the idea that one 'religion' could be 'true' and all others 'false'; the refusal to accept that religions are engaged in rivalry over this type of truth; the belief that people should continue to follow the 'ancient' traditions of their forefathers; the claim that attempts to convert people from one religion to another are futile and inappropriate; the aversion towards Christian missionaries' harangues about the 'false' gods and idolatry of the Hindus; etc. These issues were already visible in the early 18th-century reports of encounters between the Protestant missionary Bartholomäus Ziegenbalg and the 'Malabarian Brahmins' he addressed (Ziegenbalg 1719; Grafe 1972); they surface explicitly in late 18th-century and 19th-century debates between British officials and missionaries and Hindu pundits and others (Young 1981; Ali 1965). What is perhaps most striking throughout these encounters is the incomprehension on both sides; participants with a background in the Hindu traditions use the relevant vocabulary in ways very different from the language use of Western Christians and some of their Indian converts; this regularly leads to a breakdown of the conversation (Claerhout and De Roover 2005). Clearly, these recurring patterns in the conflicts about conversion cannot be attributed to a set of historically specific discourses that emerged in the first half of the 20th century. The continuity of these underlying patterns is not denied by the fact that concerns and ideas were at times articulated with new vocabulary.

Another difficulty becomes apparent when we juxtapose different historical studies concerning the tensions about conversion in India. These studies relate the conflicts to a variety of factors: Christian efforts to convert Dalits and Hindu (nationalist and upper-caste) resistance against these efforts; the historical interrelations between Hindu reform, colonial policies, cultural nationalism, concerns about minorities and their interests, mass conversion movements among the 'oppressed', etc.; the emerging Hindutva ideology ('soft' and 'hard') and the opposition by religious minorities and secularists against its claims; the fear of losing one's Hindu identity and resentment against Christian conversion as a symbol of colonial oppression; the articulation of a distinct Indian form of secularism (e.g., Bauman 2008; Chatterjee 2011; Harding 2008; Jaffrelot 2010, pp. 155-56; Josh 2009; Kim 2003; Tejani 2008). But how does one determine which among all of these factors gave shape to the post-Independence conflicts about religious conversion in India and what their respective role was?

One can point to many sets of events and discourses that preceded the Constituent Assembly and claim that these played some 'decisive' role in giving shape to the arguments of its members. But what would count as evidence for the claim that one set of factors (rather than other factors) was crucial in determining the positions and stances of these members? Of course, one could also argue that the discourses about religious freedom, conversion, and the right to propagate in the Assembly were constituted by the interplay among all of the above-mentioned factors. Thus, one ends up with Herbert Butterfield's conclusion that "the only safe piece of causation that a historian can put his hand on, the only thing which he can positively assert about the relationship between past and present" is the following: "It is nothing less than the whole of the past, with its complexity of movement, its entanglement of issues, and its intricate interactions, which produced the whole of the complex present" (Butterfield 1965, p. 19).

A third problem is the manner in which some of these accounts go about with the text of the Constituent Assembly debates. Rather than examining what its members said about the question of conversion and propagation and trying to make sense of their statements, scholars attribute positions and sentiments to these members which are not apparent from the interventions in the Assembly. Thus, Sebastian Kim explains the Constituent Assembly's disagreement as follows:

For Hindus, Hindu culture and tradition were such an integral part of their identity that religious conversion meant changing one's heritage and thus losing one's identity. It went against the tradition of 'social, moral and religious order', established by dharma ( $C A D$ Vol. 7:824-26). While Christians feared that the majority Hindus would use their social and political power to suppress conversion, Hindus resented the fact that Christians were determined to have their way over the right of conversion, which they saw as a symbol of colonial oppression. (Kim 2003, p. 58) 
Surprisingly, in the report of the session that Kim refers to, the claim that religious conversion went against the social, moral, and religious order established by dharma is nowhere to be found. One member just argues that the state should not identify with any specific religion, but that dharma does have something to contribute to the welfare of the world. In other words, Kim's interpretation not only postulates claims that are absent from the debate, but also speculates about a 'resentment' that supposedly motivates these members but which is not explicitly present in their interventions.

Similarly, Christophe Jaffrelot says the following about the debate in the Assembly: "The word 'propagate' was here a euphemism for 'proselytizing activity' and even 'conversion', terms whose emotional charge was too great" (Jaffrelot 2010, p. 155). In other words, the right to 'propagate' was inserted into the Constitution because some members had 'emotional' objections to two other words, even though these objections were not stated explicitly. Jaffrelot focuses on one intervention by Lokanath Misra, a Congress representative from Orissa, who called the Constitution "a Charter for Hindu enslavement" and objected to recognizing propagation of religion as an inalienable right (CAD, 3 December 1948, Lokanath Misra). In so doing, he ignores dozens of very different interventions equally critical of the right to propagate, but still insists that Misra's "speech" was "a good reflection of the thinking of Congress traditionalists and even of Hindu nationalists" (Jaffrelot 2010, p. 156). Thus, in today's academic study of India, it has become common to claim that the insertion of 'propagate' into Article 25 counted as a victory for the liberal forces and a defeat of Hindu traditionalists and nationalists. In the words of the historian Bhagwan Josh:

The debate in the Assembly revealed two broad ideological tendencies. On one side were those Congressmen who were, like the Hindu Mahasabha and Rashtriya Swajamsevak Sangh (RSS), opposed to the very idea of conversion and therefore did not want the word 'propagate' to be included within the Fundamental Rights. The other comprised those who were more liberal minded, aware of new developments in world public opinion and not opposed to the idea of conversion as such. But they understood it as pertaining to an 'individual' conversion. (Josh 2009, p. 101)

Finally, Josh claims that "the idea of conversion was included in the Constitution as a fundamental right despite the resistance exerted by anti-Christian forces" (Josh 2009, p. 101). Now, several members of the Assembly indeed expressed reservations vis-à-vis the constitutional recognition of a general right to convert. However, this group did not consist of Hindu nationalist and anti-Christian forces, but of people with different backgrounds: Congress members from various Hindu and other Indian traditions, a Muslim representative (Tajamul Hussain) and a secularist socialist (K. T. Shah). They argued for specific restrictions on the right to propagate religion; for instance, they objected to the converting of minors and other vulnerable groups or to the reviling of other traditions. These members were not opposed to "the idea of conversion as such," since they agreed that changing from one religion to another should always remain possible for adults, and many insisted that the right to propagate should be included in the Constitution as a concession to the Christian minority. Moreover, the advocates of a universal right to conversion in the Assembly were not "liberal minded" cosmopolitans. They were Christians, inspired by religious concerns about the relation between the conscience and God and the fundamental right to religious freedom. Hence, Josh's account superimposes a contemporary explanatory template-namely, the representation of Indian politics as an ideological struggle between Hindu nationalists and liberal minded secularists—onto a debate that occurred in the 1940s.

\section{Making Sense of the Conversion Conflict}

To gain insight into the disagreements in the Constituent Assembly, we aim to elucidate some of the recurring patterns in the Indian conflicts about conversion. From the beginning of the Independence struggle, it had been stated that the right to freedom of religion would be crucial in India given the country's religious diversity. Since conversion had long been a sensitive issue, the Constituent Assembly would need to address this in its deliberations about the constitutional clause on the freedom 
of religion. It failed to do so. As a result, religious conversion continued to generate conflict in India for decades to come, while the constitutional right to 'propagate religion' only added to this conflict. Consider the Supreme Court's landmark decision in the case of Rev. Stainislaus v. State of Madhya Pradesh (1977). Here, the Court cited a dictionary definition of 'propagate' as "to transmit or spread from person to person or from place to place" and concluded:

We have no doubt that it is in this sense, that the word 'propagate' has been used in Article 25(1), for what the Article grants is not the right to convert another person to one's own religion, but to transmit or spread one's religion by an exposition of its tenets. It has to be remembered that Article 25(1) guarantees "freedom of conscience" to every citizen, and not merely to the followers of one particular religion, and that, in turn, postulates that there is no fundamental right to convert another person to one's own religion because if a person purposely undertakes the conversion of another person to his religion, as distinguished from his effort to transmit or spread the tenets of his religion, that would impinge on the "freedom of conscience" guaranteed to all the citizens of the country alike. [1977 AIR 908/SCR (2) 611]

In other words, aiming to convert others to one's own religion constitutes an infringement of the freedom of conscience. Hence, according to the Supreme Court, the right to propagate religion cannot entail a right to convert other persons to one's own religion, but only allows one to transmit a religion by the exposition of its tenets. Predictably, this judgment caused further conflict, since it ignored the fact that certain groups in Indian society understood the freedom of conscience and the right to propagate religion very differently. Thus, two scholars have recently submitted that "the right to convert was actually included in Article 25, and, as such, the decision of the Supreme Court in Stainislaus was not only erroneous, but also led to instability in society, as Indian Christians feel they have been cheated in this matter" (Mustafa and Sohi 2017, pp. 942-43). In several ways, the ongoing disputes about conversion in India are similar to the 'debate' in the Constituent Assembly: there is strong-sometimes violent-disagreement about issues related to conversion and the propagation of religion; still, it remains unclear what the disagreement is about, what is at stake, what the conflicting positions are, and why the different parties are so emotionally involved in the issue.

Clearly, a new hypothesis is needed to begin to make sense of the Indian disputes about conversion, religious freedom, and the right to propagate religion. This hypothesis should take into account that similar discussions about questions of conversion and religious truth had been going on for more than two centuries in India before the Constituent Assembly took up this matter. In this section, we will take the first steps towards building such a hypothesis. We look at some dimensions of the dispute to develop an analysis that should also throw light upon the concerns and utterances of the Assembly members. That is, the challenge for this hypothesis is to make sense of the many disparate statements made in the Assembly and in other forums such as the Supreme Court. It should also allow us to come to some predictions about the dynamics of this conflict in India. ${ }^{6}$

\subsection{A First Approximation}

In India, the constitutional right to propagate religion has a conflict at its heart, which came to the surface in the disagreement about the conversion of minors in the Constituent Assembly. When the phrase 'to propagate religion' was introduced into the religious freedom clause, its primary reference was to Christian practices of conversion and proselytizing. In India, as elsewhere, Christians had used the word 'propagate' in relation to religion, as in 'propagation of the Gospel' or 'the propagation of

6 In today's scholarly landscape, any hypothesis that seeks to account for the Indian conflicts about conversion by conceptualizing their recurring patterns faces a risk: the charge of being 'essentialist' and 'essentializing' Christianity or the Hindu traditions. To avoid going into philosophical discussions about 'essentialism', we just wish to note the following: recognizing continuity is the precondition for describing discontinuities; that is, one is compelled to accept that there are phenomena such as Christian religion or the Hindu traditions, which show certain patterns and characteristics, in order to be able to speak about the internal diversity, plurality, and historical changes and shifts within these phenomena. 
faith'. When non-Christian Assembly members adopted the term, they initially had Christian practices in mind, for they considered the recognition of the right to 'propagate' as a concession to this minority.

The reason as to why 'propagate' was used instead of 'convert' or 'proselytize' is not of great significance to our argument: it might indicate an attempt to use more neutral and less contested wording, or it may be a coincidence. Yet, the consequences of this language usage are crucial: the inclusion of the term 'propagate religion' allowed for several conflicting understandings of the meaning and implications of the right to religious freedom. Initially, the fact that the different participants in the discussion used the same terminology led to the assumption that they were referring to the same set of phenomena when they spoke of the 'propagation of religion'. However, the situation changed when Christian representatives began to argue that the freedom to convert should be extended to minors and human beings in general as an inalienable right. This caused astonishment and surprise among other members. Suddenly, it appeared that 'the right to propagate religion' meant something different to these Christians than it did to the others.

We propose that the Assembly members who objected to conversion of minors had a shared understanding of the right to propagate which remained implicit and vague in their reasoning. Some indications are given by the fact that they referred to conversion as a Christian practice and suggested that the constitutional right to propagate simply allowed this minority to continue its practice. When these members looked at Christian practices of conversion, they saw these as this particular community's way of disseminating or spreading its religion. Therefore, the freedom to propagate religion should merely permit the Christian minority to continue this practice.

However, several members argued that the right to 'propagate' was intended for other communities also. One representative pointed out that Hindus should also educate their people "on religious tenets and doctrines" (CAD, 6 December 1948, L. Krishnaswami Bharathi). Another suggested that the Hindus and the Arya Samaj should be able to carry on their 'propaganda', much like Christians, Muslims, Jains, and Buddhists (CAD, 6 December 1948, Shri T.T. Krishnamachari). Yet another said that the freedom to propagate religion would allow any citizen "to place the benefits or beauties of his particular form of worship before others" (CAD, 3 December 1948, K. T. Shah). Thus, these speakers explained that 'propagation' also encompassed certain practices of different religions and traditions in India. The propagation of religion was not a practice unique to the Christians, but referred to a more general category of practices shared across religions. It involved educating people on the tenets and doctrines of their religion and showing others how beneficial or beautiful one's religion and its practices are; roughly then, propagation was understood as the dissemination of a religion.

The many traditions that existed on the Indian subcontinent had a variety of ways of disseminating and sharing their ideas, stories, and practices. Among the various Hindu, Jain, Sikh, and Buddhist groups in India, this could take several forms in the first half of the twentieth century: public events like festivities and processions, including amplified speeches and music; education in traditional schools; swamis giving lectures and gurus instructing pupils; teaching Sanskrit slokas to children; debates between representatives of different traditions to demonstrate which is better than the other; distributing pamphlets and copies of books; etcetera. For Assembly members who hailed from such traditions, these practices must have been familiar. We propose that they shared an intuitive categorization, however rough or fuzzy, that encompassed this type of practices.

From this perspective, Christian conversion and proselytizing become instances of this wide range of practices. These Christian practices may have some peculiar and objectionable aspects, but they happen to be the practices whereby Christians disseminate their religion and spread its tenets. Consequently, when the term 'propagation of religion' was adopted by these Assembly members, they were referring to Christian practices of 'propagation' as instances of this intuitive category of dissemination of religions. That is to say, they saw these practices in terms of characteristics that appeared to be shared with the aforementioned practices from various Indian traditions. They attributed certain salient features to the practices in question, which allowed them to recognize all these practices as instances of a category now referred to with the term 'propagation of religion'. 
As a first approximation, then, 'propagation' was understood by the majority of the Assembly members (and later by the Supreme Court judges) as the dissemination of a religion and education concerning its tenets and practices. The right to freely propagate religion entailed that the Christian minority should be free to engage in such practices, even if its specific form of propagation ('conversion') involved certain aspects which antagonized people from other communities.

\subsection{A Second Approximation}

All of this generates a basic problem: for Christians, this way of seeing conversion cannot possibly comprehend the nature of this process and the related practices of propagating religion. Naturally, these also involve sharing Christianity's 'message' through preaching and distributing pamphlets and bibles, holding public events like festivities, lectures and processions, and trying to persuade others of the value of this religion. But these are only secondary aspects of conversion. What are its primary characteristics then?

Consider the following set of claims: the God of the Bible, who is the sovereign Creator of the universe, has revealed his will in Scripture, which is his Word and not a doctrine of human origin. Therefore, propagating the Gospel is a question of spreading God's Word, rather than teaching any human idea, message, or doctrine. Being taught Christian doctrine may help a potential convert, but ultimately, the process of conversion depends upon the intervention of the biblical God into the human soul and conscience. Rather than any human practice of dissemination, it revolves around the Holy Spirit's working upon the soul because of which the sinner embarks on a process of turning to the one true God. Conversion is not a question of accepting some set of doctrines, but of submitting one's own will to God's will. Maximally, human practices can contribute to preparing people for this process-by creating 'a fertile soil', so to speak-but it is fundamentally dependent on his divine grace. Among other things, this preparation consists of creating the conditions that allow people freely to convert and respond to God's call.

While Christian groups and thinkers have conceptualized the process of conversion in many distinct ways throughout the two-thousand years of Christian history, several characteristics attributed to it have kept reoccurring: the primordial role of God in the process, the need for freedom of conscience, the restrictions on forced conversion, the limited role played by human reason and human works in the process, etc. Even if we allow for disagreement on some points, there is a simple consequence: Christian conversion cannot be a sub-set of the practices that come under the intuitive category of 'propagation of religion' held by others. For the Christian representatives who intervened in the debate, the right to propagate religion was not equivalent to the freedom to disseminate and share their traditions, tenets and practices. It was an essential right that should protect the conditions under which the soul can freely respond to God's call and to the work of the Holy Spirit, without being constrained by human fetters. 'Conversion' here could never just refer to the practices of dissemination that happen to be specific to the Christians.

In other words, for Christians, conversion is fundamentally different from any human practices of dissemination, since its essential dimension is the biblical God's intervention in the human soul and conscience and his revelation in his Word. This is why the freedom of conscience and the right to 'propagate religion' always entail the freedom to convert, and why this is "perhaps the most fundamental of Christian rights," as Frank Anthony put it (CAD, 1 May 1947). Within this framework, constraining the freedom of conversion amounts to human beings attempting to put legal and political restrictions on God's work.

\subsection{Blindness on Both Sides}

These two groups in the Constituent Assembly, and in Indian society more generally, see different things, when they look at the phenomena to which they refer as 'propagation of religion'. Both operate with a set of background ideas that have them perceive certain salient features in these phenomena. But the two ways of seeing 'propagation' are incompatible. One group sees a range of human practices 
of disseminating traditions, within which Christian practices of conversion have a place. The other group would also recognize such a category, but Christian conversion is of a different order and cannot fit along the same range. In both cases, human beings are involved, who 'preach', teach, and discuss about ideas and practices. However, because conversion ultimately embodies the biblical God's intervention, this process and the related practices make up a distinct and unique category. As a consequence, to incorporate conversion into this general set of practices of 'propagating religion' entails a denial of the core nature of this process as Christianity conceives of it.

Because of this, the two groups inevitably understand propagation of religion very differently, and use the relevant terms ('propagate', 'conversion', 'religion', 'freedom' ... ) in distinct and often incompatible ways. But this incompatibility generally remains invisible to the two parties, as it does to today's readers of these disputes, because the speakers assume that they are talking about the same things when they discuss the freedom to 'propagate religion'. It is only at certain points of rupture that the conflict suddenly becomes visible at surface level. When this happens, both groups feel misunderstood and claim the other group is inspired by prejudices. In the Constituent Assembly's exchanges about the right to propagate religion, we are witness to such moments of rupture. Most prominently, the implicit conflict of views as to the nature of propagating religion becomes explicit in the disagreement about the conversion of minors and the age of discretion.

If religious conversion is an instance of the category of practices involved in the human dissemination of 'religions', then it should stay within the limits of reason and ethics that apply to all such practices. The conversion of minors and the mentally disabled self-evidently violates these limits: it is both unreasonable and unethical, when this is what 'propagation of religion' means. It is unreasonable, as several Assembly members argued, because a child does not yet have the maturity, capacities, and experience required to determine the relative value of 'religions' and choose between them on reasonable grounds. His or her intellect and reason have not yet been sufficiently formed and cultivated. The converting of minors is also unethical because it generally involves a disruption of family life, the misleading of 'gullible' youth, and tearing up the social fabric.

However, when Christian conversion is the unique process of turning to the true God, for which the ground can be prepared by fellow humans, but which ultimately consists of the soul and conscience's response to the workings of this God, then this same set of limits cannot apply. In fact, within this framework, restricting conversion, as one would any human practice of propagation, becomes unreasonable and unethical. This is what the Christian representatives in the Assembly attempted to convey: minors also have a conscience before God, and when they feel called by him to convert to another religion, no law should ever prevent them from doing so. Since all human beings are the creatures of God, who has given each of them a conscience that can respond to his call, the act of religious conversion cannot require as a precondition a mature and well-formed intellect and knowledge of different religions and traditions.

This is not to deny that there are strands in the Christian thinking about conversion which emphasize the role of persuasion and reasoning in the act of converting and which question the legitimacy of attempts to convert children from one religion to another. Even in those arguments, however, the same basic challenge remains relevant: putting legal restrictions on the freedom of conversion would amount to subordinating the will of God to human laws; it is equivalent to oppressing the consciences of individuals simply because of their age, intellectual capacities, and origin. This should not happen, since all human beings-regardless of ethnic or religious origin, age, gender, or mental capacities-ought to be free to respond to their Creator's call to conversion. Consequently, curbing the right to propagate religion in this way is to place an "embargo absolutely on the right of conversion," as one Christian participant in the debate put it (CAD, 1 May 1947, Frank R. Anthony). Additionally, it is also unethical because parents who go through conversion cannot bring their children to the religion which they believe is the only genuine response to God's call and the sole way of saving their souls. 


\subsection{A Culture Constituted by Tradition}

How do we account for this incompatibility between two ways of seeing 'propagation of religion' and for the fact that it generally remains implicit and invisible but only becomes explicit in certain circumstances? To address this question, we first need to figure out the Indian conception of traditions and characterize how these traditions are culturally different from religions such as Christianity.

In his studies of the cultural differences between Asia and the West, S. N. Balagangadhara has theorized tradition as a type of phenomenon distinct from religions like Christianity, Judaism, and Islam (see Balagangadhara 1994, 2005, 2012). 'Tradition' refers to the ancestral traditions of different groups and communities in Asia (and elsewhere, ancient Rome, for instance). The members of such traditions continue them, not because of the alleged truth or validity of some set of beliefs or reasons, but because they have been passed on by the ancestors and transmitted from generation to generation. Such traditions, including their practices and stories, constitute communities as they evolve over time. They are both conservative and flexible: conservative because practices are generally retained unless there are good reasons to modify or discard them; flexible because the process of transmission always involves the modifying or rejecting of practices and the revising of stories and ideas.

Naturally, the Indian traditions (and Asian traditions in general) consist of more than ancestral practices and stories alone. They provide heuristics and ways of teaching which enable their members to learn to think about experience and act in the world. Generally, the many Indian traditions are oriented towards enabling the practitioner to move in the direction of 'enlightenment' or 'the dawning of knowledge'; hence, they provide a multiplicity of heuristics, signposts, and teaching methods to this effect (Balagangadhara 2005). The efficacy of such heuristics and methods depends on a range of factors, from the psychological inclinations of individuals, and their cognitive and other capacities, to the cultural context in which they have been raised. As a consequence, it does not make much sense to persuade individuals or groups of the virtues of such heuristics or methods; these are not doctrines that can be preached and accepted, since predicates of truth and falsity are not applicable to them. Rather, the question is whether or not a tradition and its heuristics are appropriate, helpful, and suitable for a certain individual. In this sense, people cannot be 'converted' into a tradition, even though they may move from one tradition to another for a variety of reasons; similarly, there may be attempts to spread a tradition, but this does not amount to having more and more individuals accept the 'truth' of a set of doctrines.

In a culture constituted by tradition, certain widely accepted clusters of ideas will dominate the reasoning about the shared practices, stories, and ideas of human groups. One such commonplace idea relates the venerability of traditions to their past and antiquity; that is, traditions are considered significant in so far as they have been transmitted and refined over many generations. Second, there is a tendency to connect each tradition to some community that claims a distinct past or to a more recent group that has crystallized around a specific teacher. Third, traditions (and their diverse practices, ideas, and stories) are considered as phenomena of human origin-implicitly so, since no need is felt to state this explicitly. Fourth, another common idea about traditions has to do with the spreading of their heuristics: these are to be disseminated in so far as they are useful to people. Members of a tradition may argue that the heuristics taught by their teachers are superior to those of any other tradition. But to suggest that one tradition should be followed by all of humanity because of its unique truth becomes implausible or even absurd against this background.

Finally, traditional practices can give rise to excesses and, when this is the case, human reason plays the role of putting constraints on these excesses. Thus, human reason plays a vital role in these traditions. It does not aim to provide the foundation for traditional practices in the sense of providing reasons or beliefs that should justify them. Instead, it puts reasonable constraints on traditions and their practices. That is, the role of reason is to prevent and constrain excesses and to allow one to carefully select and modify practices, whenever changing circumstances, differing conditions or other factors call for this. 
We suggest that this cluster of ideas about the nature of traditions is widely present in Indian society and, together with other related conceptual clusters, this constitutes the background framework which guides the intuitive reasoning of people about the traditions and practices of human communities. It provides them with a common vocabulary; it plays a central role not only in formulating thoughts about human traditions, but also in assessing the plausibility, significance, and reasonableness of such thoughts. This conception of tradition and the related cluster of ideas also determine the way in which followers of Indian traditions categorize and see the practices of other communities.

Another phenomenon of vital importance is one which we will not consider in any depth here, but which we have examined elsewhere: these widely shared clusters of background ideas concerning tradition gave shape to how Indians adopted the English language from the colonial period onwards and how they use its relevant vocabulary such as 'religion', 'conversion', 'propagation', 'freedom', and the 'right to religious freedom' (Claerhout 2014; De Roover et al. 2011). Inevitably, English-language terminology is mapped onto the natural language usage of the Indian vernaculars and their relevant vocabulary. This often results in statements that look peculiar, bizarre, and incoherent, such as several of the Assembly members' claims about the constitutional 'right' to propagate religion.

\subsection{Tradition, Propagation, and Conversion}

This hypothesis about the nature of tradition allows us to take the next step in characterizing the problems in the Indian dispute about conversion and propagation of religion. Consider the positions of Assembly members and Indian judges with a background in the Hindu, Jain, or Sikh traditions. Predictably, their reasoning with regard to 'the propagation of religion' will be shaped by the typical cluster of ideas about the nature of tradition. They see the practices, ideas, and stories of different groups in Indian society as so many traditions transmitted from generation to generation. As a consequence, in their experience, a religion like Christianity becomes just another tradition or set of traditions, which has some peculiar characteristics but constitutes a form of tradition nonetheless.

That is, in a culture dominated by tradition, Christianity comes to be viewed as the specific tradition of a community and not as the one true religion for humanity. However, this way of seeing Christianity makes one oblivious to its core structure, since this religion is held not as a human tradition but as the revelation of the biblical God to humanity. This phenomenon is confounding, since Christianity shares many elements that traditions also have: throughout their past, Christian communities also developed a set of practices and doctrines, which are products of human origin and are transmitted from generation to generation and should be assessed by means of reason. However, in their experience, the core of Christian religion is the revelation of the biblical God to humanity, which expands and spreads because of His intervention, rather than purely by human transmission. To ignore this and to see Christianity as one more tradition is perfectly understandable from the perspective of a culture dominated by tradition, but it is equivalent to being blind to the crucial difference between traditions and a religion like Christianity.

This is what happens in the Indian debate about the right to propagate religion. People with a background in the Indian traditions approach the Christian religion as one more tradition. Consequently, the propagation of religion becomes the equivalent of the dissemination of traditions and their ideas and practices. That is, they draw upon the cluster of ideas about tradition to make sense of Christian conversion and proselytization: against this background framework, conversion is no more than a transmitted practice characteristic of this tradition. In this way, the practices of dissemination of traditions, with which they are already familiar, can also serve as models to make sense of these practices of the Christians. In other words, their intuitive category of 'propagation of religion' is constituted by this conception of tradition. Inevitably, this makes them blind to the distinct nature of the Christian process of conversion, because it has them view this process as a variant of the practices whereby Indian traditions are disseminated. 
This has another consequence: if the propagation of religion is equal to the dissemination of tradition, then it has a status similar to other means of spreading human ideas and practices. That status explains why the freedom of conversion should remain within the limits of reason and ethics that apply to all such human practices. The Indian cluster of ideas concerning tradition make it unreasonable (and even absurd or unintelligible) to insist that minors or the mentally disabled should share the same freedom to convert as adults with well-developed cognitive capacities. Since moving from one tradition to another is a process guided by human deliberation, and a potentially life-changing step, it requires cognitive and emotional maturity. Hence, trying to convert children or the mentally disabled is an excessive form of the Christian practice of propagation, which should be constrained by reason.

Under these conditions, it also becomes a possibility to equate 'propagation of religion' to 'propaganda', and to see 'the right to propagate religion' as equivalent to a 'right to propaganda', as several Assembly members did. Here, 'propaganda' refers to actions aimed at spreading human ideas and institutions, including political ideology and spiritual discourse. The 'propagation of religion', to these people, becomes just a special form of propaganda, or 'propagating' and 'preaching' human ideas. Unavoidably, this generates a question: why should the propagation of religion then acquire a special status in the Constitution? From this perspective, the right to propagate religion appears redundant, since 'the right to propaganda' is already encompassed by the constitutional clauses that protect the right to free speech and freedom of expression. As Munshi put it, even if the word 'propagate' were not there, "I am sure, under the freedom of speech which the Constitution guarantees it will be open to any religious community to persuade other people to join their faith" (CAD, 6 December 1948, K. M. Munshi). Or, in the words of another member, "after all, propagation is merely freedom of expression" (CAD, 6 December 1948, Shri K. Santhanam).

In contrast, in Christianity, the propagation of faith (or 'propagandum Fidei' in Latin) cannot merely be a specific form of propaganda to be subsumed under the right to freedom of expression. For Catholic Christians, the propagation of faith is intertwined with the very nature of the Church. As the Bible has it, the Church is divinely sent to the nations of the world to be unto them "a universal sacrament of salvation" (Mark 16:16). Following in the footsteps of Christ, the Apostles "preached the word of truth and begot churches" and it is the duty of the Church to continue this task "so that the word of God may run and be glorified" (2 Thess. 3:1). In other words, the kingdom of God should be proclaimed and established throughout the world. This also describes the duties of the Church's Society for the Propagation of the Faith. Things are not so different for Protestants, even though they would deny the status of the Roman-Catholic Church as a divinely-sent institution. For instance, the Society for the Propagation of the Gospel in Foreign Parts, an Anglican missionary organization active on the Indian subcontinent, had as its objective to show "the greatest Charity" to the souls of men by bringing the natives into "the Sheep-fold of our blessed Saviour" through "the use of the means of Grace" (Pascoe 1901 , p. 8). However, unless blessed by God, this charitable work is worth nothing, as a popular English hymn about missionary work from this period, titled God is working his purpose out, made clear: "All that we do can have no worth, unless God bless the deed; vainly we hope for the harvest-tide, till God gives life to the seed" (Pascoe 1901, p. iii).

For Christians, then, the propagation of faith has an extraordinary status: it is propagating the Word of God, rather than any human message or ideology; it is part of proclaiming and establishing the kingdom of God throughout the world, rather than spreading the scope of some human tradition, movement, or institution. Here, it would be unacceptable to reduce the propagation of religion to 'propaganda', similar to propagating mere human ideas and institutions, and to suggest that the right to propagate religion is redundant since it is already covered by the freedom of speech or expression. This would be to reduce the Word of God to the status of human opinion and the doing of God's work to the equivalent of ideological propaganda. In the Christian religion, this will always be intolerable. 


\subsection{The Limits of Propagation?}

By now, it should be clear that the conflict about conversion in India is not a clash between a party that opposes the freedom to propagate religion and one that defends this freedom; it is not a question of being pro- or anti-conversion; and it is certainly not a conflict between Hindu nationalists, who feel threatened by the recognition of the right to convert, and progressive or liberal-minded secularists, who wish to safeguard this fundamental right for the minorities and lower castes. This type of explanation amounts to misrepresentation of the Indian dispute about the right to propagate.

The intensity of the conflict over conversion has only grown in India in the decades that followed the enacting of the Constitution in 1950. The challenge confronting our alternative analysis is to make sense of this enduring conflict. How would our proposal allow us to predict the structure and dynamics of the lasting disputes about conversion?

Currently, we can only take a few steps towards answering this question. One crucial step is the realization that we are not only facing a conflict between two background frameworks or clusters of ideas: an Indian conception of the dissemination of tradition and Christian claims about the process of conversion. The two parties involved in the dispute also experience the conflict in two incompatible ways. One sees it as a question of imposing reasonable limits on (the excesses of) the Christian practices of conversion, which are viewed as instances of the human dissemination of tradition; for them, attempts to convert others that go beyond these limits are violations of the freedom of religion and conscience. The other sees it as the imposition of unreasonable limits on the process of conversion, which is primarily shaped by the biblical God; for them, it is obvious that the freedom to convert is essential to the freedom of religion and conscience. Both share a blindness to each other's experience of the conflict.

If this is the case, we can infer some basic predictions as to the further development of the conflict over conversion in India. The same set of issues should recur over and again, without giving rise to effective legal solutions. In fact, as the implicit clash becomes visible at surface level, these issues will get exacerbated. People reasoning against the background of one framework will find it increasingly difficult to digest that the propagation of religion should allow certain groups to try and convert members of other groups by means considered intrusive and unreasonable. When it becomes clear to them that Christian conversion cannot fit within the propagation of religion, as they intuitively understand this category, they will find this practice objectionable and call for legal restrictions. They will not see any conflict between recognizing the constitutional right to propagate religion and yet imposing such restrictions on conversion. Groups reasoning against the second background framework, in contrast, will find it increasingly objectionable that their practices of conversion are subordinated to unreasonable and discriminatory legal constraints.

Do these predictions help us to understand the clash over conversion in India as it has developed since the 1950s? This is what future research will have to examine. At first sight, the hypothesis looks promising, since it appears to allow us to make sense of specific developments. For instance, during the past decades, legislation has been passed by several state governments that seeks to restrict conversion in the name of freedom of religion. As noted, the Supreme Court also argued that the freedom to propagate religion does not entail a right to convert others, since conversion conflicts with the freedom of conscience once it goes beyond propagation understood as the transmission of the tenets of a religion. Our proposal holds the potential to show why such apparently unreasonable laws and legal decisions nevertheless make sense to Indian legislators and judges.

\section{Conclusions}

Before concluding, we need to highlight some potential risks of misunderstanding our analysis. The first can be put in the form of a question: Are we arguing that Indian Christians or Muslims are any less Indian, because they do not share the same conception of tradition? This type of question is misguided, since there is no sound way of conceptualizing and measuring the 'Indianness' of individuals. Moreover, it is also unproductive, for it conceals far more promising research questions. 
In the Constituent Assembly, we saw a Muslim representative take positions that appear to be constituted by the Indian conception of tradition. He questions the right to propagate religion: "Why should you interfere with my religion and why should I interfere with your religion?" (CAD, 3 December 1948, Tajamul Husain). From this, we can infer that some Indian Muslims adopted these background ideas about tradition. A similar phenomenon is visible in Frank Anthony's explicit declaration that his community of Anglo-Indian Christians neither propagates nor converts (CAD, 1 May 1947). To allow for this, the way in which such Indian Muslims and Christians experience and practice their respective religions in India must have taken a distinct form, where the spreading of 'true religion' is subordinated to other dynamics.

This raises the general question as to how religions like Islam and Christianity begin to change when they are embedded in a cultural setting constituted by the phenomenon of tradition, such as Indian culture. How do their attitudes and ideas concerning religion take new and different forms, when they operate in a larger framework of Indian traditions? Obviously, formulating and answering this question requires extensive research, but it indicates that there are routes to think about the relationship between Indian culture and a religion like Christianity, which are more fruitful than the increasingly barren debates about religion and conversion in contemporary India.

A second risk of misunderstanding the hypothesis is that we are merely suggesting that the Constituent Assembly members failed to understand Western-Christian notions of 'religion', 'conversion', 'rights', and 'freedom'. This is not our claim. Instead, we wish to draw attention to the fact that cultural difference is relevant to understanding the dispute about conversion and religion in India. When people with a background in the Indian traditions voice concerns about propagation and conversion, they are implicitly stating a cultural conception of tradition, which has so far been ignored in the debate and in academic analysis. The fact that they appear to use the English language-and its vocabulary like 'religion', 'propagate', and 'conversion'-fluently has been misleading. Because of their usage of these words, their concerns are easily distorted. Many of their concerns about conversion and propagation of religion have been swept under the rug as though they simply reflect a 'Hindu nationalist ideology' and are irrelevant to the question of religious freedom. This not only misrepresents the Indian conflict about conversion but also prevents us from understanding the real concerns and finding solutions.

Even more, it covers up another question: how is it possible that Indian 'secularists' and political leaders like Nehru and Ambedkar found it obvious that the freedom of conscience and religion should entail the right to convert others to one's own religion? Why did they ignore the reasoning of the critics of conversion in the Constituent Assembly and elsewhere? And why is it so self-evident to Western commentators and to international bodies like the United Nations that the legal restrictions on conversion in India constitute violations of the right to religious freedom? These questions are significant because the secular intelligentsia seem to be reproducing a Christian position on the freedom of conscience and the right to convert, as though this is the self-evident and rational option, while ignoring the concerns generated by the Indian conception of tradition.

Understood against the background of a culture constituted by tradition, the fact that one argues for constraints on religious conversion is not incoherent with simultaneously advocating the freedom to propagate religion. From this perspective, the freedom of religion includes the freedom for the Christians to continue their practices, even if one of those practices comprises a peculiar and often objectionable form of 'transmitting the tenets of religion'. So long as this practice of conversion remains within certain limits of reason and ethics, Christians should be free to partake in it; when it goes beyond those limits, it becomes an intrusion into the freedom of religion of others. Against this background, then, Article 25 includes the freedom for Christians to continue their practices ('conversion') but within the limits set by the Indian conception of tradition and its notions of dissemination ('propagation'). Future research will have to show whether this hypothesis can help unravel the continuing dispute about conversion and religious freedom in India.

Author Contributions: Both authors have contributed equally to this research article. 
Funding: This research received no external funding.

Conflicts of Interest: The authors declare no conflict of interest.

\section{References}

Adcock, Catherine S. 2014. The Limits of Tolerance: Indian Secularism and the Politics of Religious Freedom. New York: Oxford University Press.

Ahmad, Tariq. 2018. Report: State Anti-Conversion Laws in India. The Law Library of Congress: Global Legal Research Center. Available online: https:/ /www.loc.gov/law/help/anti-conversion-laws/india-anticonversion-laws.pdf (accessed on 2 November 2018).

Ali, Muhammad Mohar. 1965. The Bengali Reaction to Christian Missionary Activities 1833-1857. Chittagong: Mehrub Publications.

Ambedkar, Bhim Rao. 1947. States and Minorities. Available online: https://cadindia.clpr.org.in/historical_ constitutions/states_and_minorities_dr_b_r_ambedkar_1945_1st\%20January\%201945 (accessed on 24 October 2018).

Armstrong, Guyda, and Ian N. Wood, eds. 2000. Christianizing Peoples and Converting Individuals. Turnhout: Brepols Publishers.

Balagangadhara, S. N. 1994. "The Heathen in His Blindness ... ": Asia, the West, and the Dynamic of Religion. Leiden: Brill.

Balagangadhara, S. N. 2005. How to Speak for the Indian Traditions: An Agenda for the Future. Journal of the American Academy of Religion 73: 987-1013. [CrossRef]

Balagangadhara, S. N. 2012. Reconceptualizing India Studies. New Delhi: Oxford University Press.

Bauman, Chad. 2008. Christian Identity and Dalit Religion in Hindu India, 1868-1947. Grand Rapids: Wm. B. Eerdmans Publishing Co.

Bauman, Chad. 2015. Pentecostals, Proselytization, and Anti-Christian Violence in Contemporary India. Oxford: Oxford University Press.

Butterfield, Herbert. 1965. The Whig Interpretation of History. New York and London: W.W. Norton. First published 1931.

Chatterjee, Nandini. 2011. The Making of Indian Secularism: Empire, Law and Christianity 1830-1960. New York: Palgrave Macmillan.

Citron, Bernhard. 1951. New Birth: A Study of the Evangelical Doctrine of Conversion in the Protestant Fathers. Edinburgh: Edinburgh University Press.

Claerhout, Sarah. 2014. Gandhi, Conversion, and the Equality of Religions: More Experiments with Truth. Numen: International Review for the History of Religions 61: 53-82. [CrossRef]

Claerhout, Sarah, and Jakob De Roover. 2005. The Question of Conversion in India. Economic and Political Weekly 40: 3048-55.

Claerhout, Sarah, and Jakob De Roover. 2008. Conversion of the World: Proselytization in India and the Universalization of Christianity. In Proselytization Revisited: Rights Talk, Free Markets and Culture Wars. Edited by Rosalind I. J. Hackett. London: Equinox, pp. 53-76.

Coleman, Jennifer R. 2008. Authoring (In)authenticity, Regulating Religious Tolerance: The Implications of Anti-Conversion Legislation for Indian Secularism. Cultural Dynamics 20: 245-77. [CrossRef]

Dayananda, Saraswati Swami. 1999. Conversion is Violence: Open Letter to His Holiness the Pope John Paul II. The Indian Express, October 29.

De Roover, Jakob, Sarah Claerhout, and S. N. Balagangadhara. 2011. Liberal Political Theory and the Cultural Migration of Ideas: The Case of Secularism in India. Political Theory 39: 571-99. [CrossRef]

Grafe, Hugald. 1972. Hindu Apologetics at the Beginning of the Protestant Mission Era in India. Indian Church History Review 6: 43-69.

Harding, Christopher. 2008. Religious Transformation in South Asia: The Meanings of Conversion in Colonial Punjab. Oxford: Oxford University Press.

Harran, Marilyn J. 1983. Luther on Conversion: The Early Years. Ithaca and London: Cornell University Press.

Heredia, Rudolf C. 2007. Changing Gods: Rethinking Conversion in India. New Delhi: Penguin Books.

Huff, James Andrew. 2009. Religious Freedom in India and Analysis of the Constitutionality of Anti-Conversion Laws. Rutgers Journal of Law and Religion 10: 3-7. 
Jaffrelot, Christophe. 2010. Religion, Caste and Politics in India. Delhi: Primus Books.

Jenkins, Laura Dudley. 2008. Legal Limits on Religious Conversion in India. Law and Contemporary Problems 71: 109-27.

Josh, Bhagwan. 2009. Conversion, Complicity and the State in Post-Independence India. In Christianity and the State in India: Complicity and Conflict. Edited by Julius Bautista and Francis Khek. Abingdon: Routledge, pp. 97-114.

Kim, Sebastian. 2003. In Search of Identity: Debates on Religious Conversion in India. New Delhi: Oxford University Press.

Morrison, Karl F. 1992. Understanding Conversion. Charlottesville: University Press of Virginia.

Muldoon, James, ed. 1997. Varieties of Religious Conversion in the Middle Ages. Gainesville: University Press of Florida.

Mustafa, Faizan, and Jagteshwar Singh Sohi. 2017. Freedom of Religion in India: Current Issues and Supreme Court Acting as Clergy. Brigham Young University Law Review 2017: 915-55.

Osuri, Goldi. 2013. Religious Freedom in India: Sovereignty and (Anti) Conversion. London and New York: Routledge.

Pascoe, C. F. 1901. Two Hundred Years of the S. P. G.: An Historical Account of the Society for the Propagation of the Gospel in Foreign Parts, 1701-1900. London: The Society's Office.

Rao, Shiva B. 2015. The Framing of the India's Constitution: Select Documents. Volume II. New Delhi: Universal Law Publishing Co. Ltd. First published 1967.

Roberts, Nathaniel. 2016. To Be Cared For: The Power of Conversion and Foreignness of Belonging in an Indian Slum. Oakland: University of California Press.

Robinson, Rowena, and Sathianathan Clarke, eds. 2003. Religious Conversion in India: Modes, Motivations, and Meanings. New Delhi: Oxford University Press.

Sarkar, Sumit. 2007. Christian Conversions, Hindutva, and Secularism. In The Crisis of Secularism in India. Edited by Rajeswari Sunder Rajan and Anuradha Dingwaney Needham. Durham: Duke University Press, pp. 356-68.

Tejani, Shabnum. 2008. Indian Secularism: A Social and Intellectual History, 1890-1950. Bloomington: Indiana University Press.

Tellenbach, Gerd. 1991. Church, State and Christian Society at the Age of the Investiture Contest. Translated by R. F. Bennett. Toronto: University of Toronto Press. First published 1936.

Viswanathan, Gauri. 1998. Outside the Fold: Conversion, Modernity, and Belief. Princeton: Princeton University Press. Wicks, Jared. 1992. Luther's Reform: Studies on Conversion and the Church. Mainz am Rhein: von Zabern.

Young, Richard Fox. 1981. Resistant Hinduism: Sanskrit Sources on Anti-Christian Apologetics in Early Nineteenth-Century India. Publications of the De Nobili Research Library. Vienna: Institut für Indologie der Universität Wien, vol. VIII.

Ziegenbalg, Bartholomeus. 1719. Thirty Four Conferences Between the Danish Missionaries and the Malabarian Bramans (or Heathen Priests) in the East Indies, Concerning the Truth of the Christian Religion. Translated by Philipps. London: H. Clements.

(C) 2019 by the authors. Licensee MDPI, Basel, Switzerland. This article is an open access article distributed under the terms and conditions of the Creative Commons Attribution (CC BY) license (http://creativecommons.org/licenses/by/4.0/). 